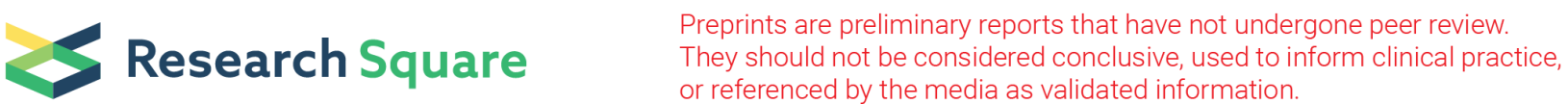 \\ Effects of Structural Symmetry on NMR Spectra of 3,9-Diazatetraasteranes
}

\section{Runzhi Sun}

Beijing University of technology Faculty of environment and life

\section{Xiuqing Song}

Beijing university of technology faculty of environment and life

\section{Fan Xie}

Beijing university of technology Faculty of environment and life

\section{Huiqin Wang}

Beijing university of technology Faculty of environment and life

Hong Yan ( $\sim$ hongyan@bjut.edu.cn )

Beijing University of Technology https://orcid.org/0000-0002-3176-7912

\section{Research Article}

Keywords: C2-3,9-diazatetraasteranes, non-C2-3,9-diazatetraasterane, structural symmetry, NMR analysis, X-ray diffraction analysis

Posted Date: September 7th, 2021

DOl: https://doi.org/10.21203/rs.3.rs-863872/v1

License: (c) (1) This work is licensed under a Creative Commons Attribution 4.0 International License. Read Full License 


\section{Abstract}

The structural symmetry is of great significance on the unique physical and chemical properties that closely related to pharmacological applications. To investigate the effects of structural symmetry on the NMR spectra, C2-3,9-diazatetraasteranes and non-C2-3,9-diazatetraasteranes were selected as the research object. They were synthesized by the self-dimerization and cross-dimerization of diethyl 1,4dihydropyridine-3,5-dicarboxylates, respectively. The differences and similarities in NMR spectra of these two types of 3,9-diazatetraasteranes were discussed by the 1D-NMR and 2D-NMR analysis. The singlecrystal X-ray diffraction (XRD) was used to demonstrate directly their structural symmetry.

\section{Introduction}

Tetraasterane is a class of caged hydrocarbons or polyhedra consisting of four cyclohexanes and two parallel cyclobutanes. The familiar polyhedra are norbornene, adamantine and cubane, etc. All of them have been used as scaffolds or agents in the drug and agrochemical discovery with the high symmetry and lipophilic properties [1-3]. The tetraasterane was synthesized by a dimerization of 1,4cyclohexadiene derivatives, while the 3,9-diazatetraasterane was aza-analogous of tetraasterane and synthesized by a dimerization of 1,4-dihydropyridine derivatives [4-6]. With a $C_{2}$ symmetric property, the $C_{2}$-3,9-diazatetraasteranes was synthesized via the self-dimerization of the 1,4-dihydropyridines, which exhibited anti-HIV-1 protease activity, anti-tumor activities, modulating multidrug resistance (MDR) towards P-glycoprotein, and other physiological and pharmacological activities [7-12]. While non- $C_{2}-3,9-$ diazatetraasteranes was synthesized via the cross-dimerization of different 1,4-dihydropyridines [13]. As stated in the literature, the different geometric configurations and isomers of molecules may manifest various physical and chemical properties $[14,15]$. In this sense, the change of structural symmetry in the molecular structure was indispensable in biochemistry, pharmacology and supramolecular chemistry. Especially in caged hydrocarbons, the NMR complexity was also a closely related to the structural symmetry. Herein, two kinds of 3,9-diazatetraasteranes (1 and 2 ) were selected as the research objects to investigate the effects of structural symmetry on the NMR spectra (Scheme 1). The NMR spectra of $\mathrm{C}_{2}$ 3,9-diazatetraasterane and non- $C_{2}-3,9$-diazatetraasterane were analyzed using 1D-NMR and 2D-NMR spectra. The single-crystal X-ray diffraction (XRD) was used to further analyze the structural symmetry of the title compounds.

\section{Results And Discussion 2.1 Chemical synthesis}

Based on the previously reported, a conventional strategy was used to synthesize 3,9-diazatetraasterane (1 and 2), as shown in Scheme 2. $C_{2}-3,9$-diazatetraasterane 1 was prepared by the self-dimerization of diethyl 4-phenyl-1,4-dihydropyridine-3,5-dicarboxylate 3 and diethyl 1,4-diphenyl-1,4-dihydropyridine-3,5dicarboxylate $\mathbf{4}$ in tetrahydrofuran solution with $\gamma$-cyclodextrin. The $\gamma$-cyclodextrin was used to 
manipulate the two 1,4-dihydropyridine molecules to be arranged in parallel, so as to promote formation of cage-dimer in the optimal conformation, which could improve the yields of $C_{2}$-3,9-diazatetraasterane 1. $\mathbf{1 a}$ and $\mathbf{1 b}$ were obtained from the 1,4-dihydropyridine 3 and 1,4-dihydropyridine $\mathbf{4}$ for $10 \mathrm{~h}$ irradiation by $250 \mathrm{~W}$ medium-pressure mercury lamp in tetrahydrofuran solution with $y$-cyclodextrin. The yields of 1a and $1 \mathrm{~b}$ were $80 \%$ and $82 \%$, respectively. The non- $C_{2}-3,9$-diazatetraasterane 2 was prepared by the crossdimerization of 1,4-dihydropyridines 3 and 4 , or 3 and diethyl 4-(3,4,5-trimethoxyphenyl)-1,4dihydropyridine-3,5-dicarboxylate $\mathbf{5}$. 2a and $\mathbf{2 b}$ were obtained from $\mathbf{3}$ and $\mathbf{4}$, or $\mathbf{3}$ and $\mathbf{5}$ irradiated for $\mathbf{8} \mathrm{h}$ by UV light of $365 \mathrm{~nm}$ in methanol. On account of the self-dimerization of 1,4-dihydropyridines $\mathbf{3}, \mathbf{4}$ and $\mathbf{5}$, the $\mathbf{2}$ yields decreased. The yields of $2 a$ and $\mathbf{2 b}$ were $30 \%$ and $28 \%$, respectively. The structures of $\mathbf{1}$ and 2 were confirmed by ${ }^{1} \mathrm{H} N M R,{ }^{13} \mathrm{C}$ NMR, high-resolution mass spectrometry and X-ray diffraction analysis.

\subsection{NMR analysis \\ 2.2.1 NMR characterization}

The NMR spectra of $C_{2}-3,9$-diazatetraasterane 1 were analyzed using 1D-NMR and 2D-NMR spectra. In the ${ }^{1} \mathrm{H}$ NMR spectrum of $1 \mathrm{a}$ (Fig. $1 \mathrm{~A}$ ), the most obvious peak in all proton spectra appeared at $\delta 0.98 \mathrm{ppm}$ demonstrated the triple peak, which belonged to the absorption signal of two methyl groups in the ethyl group on both sides of the piperidine ring. The broad peak at $\delta 3.02 \mathrm{ppm}$ was the absorption peak of $\mathrm{NH}$. The multiple peaks at $\delta 3.88-4.01 \mathrm{ppm}$ were the absorption peaks of the two methylene groups $\left(-\mathrm{OCH}_{2}\right)$ in the ethyl group, due to the spatial structure of the molecule that the two hydrogen atoms were located in an inequivalent magnetic field. The single peak at $\delta 3.95 \mathrm{ppm}$ was the absorption peak of the methyne group (-CH) at the 4- position of the piperidine ring. In the HSQC spectrum (Fig. 2A and Fig. 3), the proton peak at $\delta 3.95 \mathrm{ppm}$ with the $\delta 43.82 \mathrm{ppm}{ }^{13} \mathrm{C}$ NMR signal showed a correlation, so it could be determined that the singlet belonged to the prow protons. The single peak at $\delta 4.32 \mathrm{ppm}$ was the absorption signal of the four cyclobutane protons $(-\mathrm{CH})$. The three groups of multiple peaks at $\delta 7.16-7.55 \mathrm{ppm}$ belonged to the aromatic protons $(-\mathrm{CH})$ on the benzene ring. In the $\mathrm{H}-\mathrm{H}$ COSY spectrum (Fig. 2B and Fig. 5), two groups of obviously correlated proton peaks $\left(-\mathrm{CH}_{3}\right.$ protons at $\delta 0.98 \mathrm{ppm}$ with $-\mathrm{CH}_{2}$ protons at $\delta 3.94 \mathrm{ppm}$ and aromatic protons at $\delta 7.19 \mathrm{ppm}$ with aromatic protons at $\delta 7.53 \mathrm{ppm}$ ) further confirmed the structural symmetry of $1 \mathrm{a}$. Similarly, the $\mathbf{1 b}$ displayed an analogous proton NMR spectrum for its exact centrosymmetry (Fig. 1B), the signals for methyl protons $\left(-\mathrm{CH}_{3}\right)$ at $\delta 0.97 \mathrm{ppm}$, the signals for methylene protons $\left(-\mathrm{OCH}_{2}\right)$ at $\delta 3.93-4.05 \mathrm{ppm}$, the reason for the split was the same as $1 \mathrm{a}$. A singlet at $\delta 3.98 \mathrm{ppm}$ was the absorption peak of the methyne group $(-\mathrm{CH})$ at the 4-position of the piperidine ring, a singlet from the cyclobutane protons $(-\mathrm{CH})$ at $\delta 5.32 \mathrm{ppm}$, a doublet, a quartet and a multiplet from the aromatic protons $(-\mathrm{CH})$ were located at $\delta 6.92-7.01 \mathrm{ppm}, \delta 7.08 \mathrm{ppm}$ and $\delta 7.37 \mathrm{ppm}$.

Compared the NMR data of 1 , the non- $C_{2}-3,9$-diazatetraasterane 2 with axisymmetric and central symmetry showed a relatively complex proton spectra (Fig. 1C and Fig. 1D). On account of its asymmetry of $2 \mathrm{a}$, there were two triplet from the methyl groups $\left(-\mathrm{CH}_{3}\right)$ at $\delta 0.95$ and $1.00 \mathrm{ppm}$, a broad peak at $\delta 3.02$ ppm was the absorption peak of $\mathrm{NH}$, a single peak from the methyne group at the 4-position of the 
piperidine ring $(-\mathrm{CH})$ at $\delta 3.91 \mathrm{ppm}$, a multiple peak at $\delta 3.91-4.03 \mathrm{ppm}$ from the methlene protons of the ethyl ester group $\left(-\mathrm{OCH}_{2}\right)$, two singlet from the cyclobutane protons $(-\mathrm{CH})$ at $\delta 4.41$ and $5.21 \mathrm{ppm}$, three multiplet from the aromatic protons $(-\mathrm{CH})$ at $\delta 6.92-6.96,7.03-7.24$ and $7.29-7.57 \mathrm{ppm}$. Similarly,in the proton NMR spectrum of $\mathbf{2 b}$, the methyl groups $\left(-\mathrm{OCH}_{2} \mathrm{CH}_{3}\right)$ were observed at $\delta 1.00$ and $1.05 \mathrm{ppm}$, the absorption peak of $\mathrm{NH}$ were located at $\delta 3.04 \mathrm{ppm}$, the methoxy groups $\left(-\mathrm{OCH}_{3}\right)$ at $\delta 3.80$ and $3.81 \mathrm{ppm}$, the methyne groups $(-\mathrm{CH})$ at the 4-position of the piperidine ring at $\delta 3.87$ and $3.91 \mathrm{ppm}$, the methylene groups $\left(-\mathrm{OCH}_{2}\right)$ from ethyl ester group at $\delta 3.95-4.04 \mathrm{ppm}$, the cyclobutane protons $(-\mathrm{CH})$ at $\delta 4.33$ and $4.34 \mathrm{ppm}$, the aromatic protons $(-\mathrm{CH})$ from the benzene ring substituted by methoxy at $\delta 6.88 \mathrm{ppm}$, another aromatic protons $(-\mathrm{CH})$ at $\delta 7.15-7.23$ and $7.53 \mathrm{ppm}$. The ${ }^{1} \mathrm{H}$ NMR spectra of $\mathbf{2 a}$ and $\mathbf{2 b}$ was much more complicated and informative. Due to the asymmetry of the structure, two conspicuous triplets from the methyl groups at $\delta 0.95 \mathrm{ppm}$ and $1.00 \mathrm{ppm}$ were observed (Fig. 1C) in the ${ }^{1} \mathrm{H}$ NMR spectrum of 2a. Similarly, the same proton peaks at $\delta 1.00 \mathrm{ppm}$ and $1.05 \mathrm{ppm}$ were in the ${ }^{1} \mathrm{H}$ NMR spectrum of $2 \mathrm{~b}$ (Fig. 1D). The methylene groups of 2 also split into multiplet at $\delta 3.91-4.03 \mathrm{ppm}$ and $\delta 3.95-4.04 \mathrm{ppm}$, respectively. And the reason was the same as 1 , because the two hydrogen protons of the methylene group were not equivalent.

Table 2

Comparison of chemical shifts (ppm) for compounds $1 \mathrm{a}, \mathbf{1 b}, \mathbf{2 a}$ and $\mathbf{2 b}$

\begin{tabular}{|lllll|}
\hline & $\mathbf{1 a}$ & $\mathbf{1 b}$ & $\mathbf{2 a}$ & $\mathbf{2 b}$ \\
\hline Methyl protons & $\mathrm{t}, 0.98$ & $\mathrm{t}, 0.97$ & $\mathrm{t}, 0.95,1.00$ & $\mathrm{t}, 1.00,1.05$ \\
\hline Methene protons & $\begin{array}{l}\mathrm{m}, 3.88- \\
4.01\end{array}$ & $\begin{array}{l}\mathrm{m}, 3.93- \\
4.05\end{array}$ & $\mathrm{~m}, 3.91-4.03$ & $\mathrm{~m}, 3.95-4.04$ \\
\hline Methoxy protons & - & - & - & $\mathrm{d}, 3.80,3.81$ \\
\hline $\mathrm{NH}$ groups & $\mathrm{brs}, 3.02$ & - & $\mathrm{brs}, 3.02$ & 3.04 \\
\hline Prow protons & $\mathrm{s}, 3.95$ & $\mathrm{~s}, 3.98$ & $\mathrm{~s}, 3.91$ & $\mathrm{~s}, 3.87,3.91$ \\
\hline $\begin{array}{l}\text { Cyclobutane } \\
\text { protons }\end{array}$ & $\mathrm{s}, 4.32$ & $\mathrm{~s}, 5.32$ & $\mathrm{~s}, 4.41,5.21$ & $\mathrm{~d}, 4.33,4.34$ \\
\hline $\begin{array}{l}\text { Aromatic } \\
\text { protons }\end{array}$ & $\mathrm{m}, 7.16-$ & $\mathrm{m}, 6.92-$ & $\mathrm{m}, 6.92-6.96,7.03-7.24$, & $\mathrm{m}, 6.88,7.15-7.23$, \\
\hline
\end{tabular}

\subsubsection{Comparative analysis of NMR spectra}

By comparison of the ${ }^{1} \mathrm{H}$ NMR spectrum of 1 and 2 , it was not difficult to find that the structural symmetry had effects on the splitting of the methyl protons from ethyl ester group and cyclobutane protons. In the ${ }^{1} \mathrm{H}$ NMR spectra of $\mathbf{1 a}$ and $\mathbf{1 b}$, the absorption peak of methyl groups in the ethyl ester group was a triplet, respectively (Fig. 1A and Fig. 1B), which was due to the hydrogen atom of the methyl group was located at the tail of the ethyl ester group and could be fast rotated by the $\mathrm{C}-\mathrm{C}$ single bond to eliminate the magnetic inequivalence. A special split phenomenon also could be found easily, which was 
a multiplet from methylene protons. From the perspective of the spatial structure of the molecule, the hydrogen atom pairs of the methylene group were in an inequivalent magnetic field [16]. One of the ethyl ester groups (C6-02-C7-C8) in 1a was chosen to explain this phenomenon. The molecular structure of 1 has a mirror surface passing through two nitrogen atoms and two 4-position carbon atoms at phenyl and a symmetry center in the center of the cage (Fig. 7A). As a result, all four ethyl groups were chemically equivalent in 1a. The whole molecule was symmetrical, while along the pseudo-axially oriented the aryl groups and $\mathrm{H} 2$ almost equally divided the cage. One of the methylene protons was closed to the phenyl ring, and the other was nearby $\mathrm{H} 7 \mathrm{~A}$, resulting in the two hydrogen atoms of methylene were in an inequivalent magnetic field. Therefore, theoretically the splitting form of the methylene group should be a double quartet and the integral ratio of four peaks was 1:3:3:1 by the homonuclear ${ }^{2} \mathrm{~J}$-coupling (from geminal protons of methylene group) and heteronuclear ${ }^{3} \mathrm{~J}$-coupling (from vicinal protons of methyl group), due to the partial signal overlap, it was replaced by a multiplet as shown in Fig. 1A. The carbonproton correlation of the $\delta 3.93 \mathrm{ppm}$ proton singlet with the $\delta 43.82 \mathrm{ppm}{ }^{13} \mathrm{C}$ NMR signal in the HSQC spectrum provided the means to assign the singlet to the prow protons. The correlation of the $\delta 3.88-$ $4.01 \mathrm{ppm}$ proton multiplet with the $\delta 60.84 \mathrm{ppm}{ }^{13} \mathrm{C}$ NMR signal in the HSQC spectrum provided the means to assign this multiplet to the methylene protons (Fig. 2A and Fig. 3), which further explained the central symmetry of $1 \mathrm{a}$.

It was not difficult to find that the structural symmetry also had effects on the shift and splitting of the cyclobutane protons of 1 and 2 . The shift of $1 \mathrm{a}$ was at $\delta 4.32 \mathrm{ppm}$, but the $1 \mathbf{b}$ was at $\delta 5.32 \mathrm{ppm}$. On account of in $1 \mathrm{a}$, the hydrogen atom on the piperidine ring was connected to the nitrogen atom, and in $1 \mathrm{~b}$, the phenyl group was connected, the p-r conjugation between nitrogen atom and the phenyl group. The electron cloud density was reduced and enhanced deshielding, the signal shift moved to the low field. The cyclobutane protons split between $\mathbf{1}$ and $\mathbf{2}$ was somewhat different. The $\mathbf{2 a}$ and $\mathbf{2 b}$ had similar peak shapes, because of their asymmetric structure. The four cyclobutane protons in compound $2 \mathrm{a}$ was two singlets at $\delta 4.41$ and $5.21 \mathrm{ppm}$ (Fig. 1C), and in $2 \mathrm{~b}$ was a doublet at $\delta 4.33$ and 4.34 ppm (Fig. 1D). In the spectrum of the HSQC of compound $\mathbf{2 b}$ (Fig. 4), the carbon-proton corrections of the $\delta 4.33$ and 4.34 ppm proton singlets with the $\delta 55.0,55.2 \mathrm{ppm}{ }^{13} \mathrm{C}$ NMR signals in the HSQC spectrum to verify the two singlets belonged to the four cyclobutane protons. And in the spectrum of $1 \mathrm{a}$ (Fig. 3), the corrections of the $\delta 4.32 \mathrm{ppm}$ proton singlets with the $\delta 55.10 \mathrm{ppm}{ }^{13} \mathrm{C}$ NMR signal belonged to the four cyclobutane protons. The reasons for the splitting of cyclobutene was similar to that of methylene. Introduction of a methoxy group on the phenyl group in $\mathbf{2 b}$ resulted in a change in the steric environment of the cyclobutane protons, as a result, the protons on both sides of the same cyclobutane were inequivalent, and the two cyclobutane protons on the same piperdine ring were equivalent. So that the cyclobutane protons of $\mathbf{2 b}$ had two singlet peaks, and that of $\mathbf{1 a}$ in a singlet.

\subsection{X-ray diffraction analysis}

In order to further analyze the influence of the structural symmetry of 1 and 2 , the single-crystal X-ray diffraction analysis of compounds $1 \mathbf{a}$ and $\mathbf{2 b}$ were carried out (Fig .7). The geometry of the piperidine ring and cyclobutane of $\mathbf{1 a}$ and $\mathbf{2} \mathbf{b}$ were demonstrated in Table 3 , Table 4 and Table 5. By comparing the 
torsion angles, the bond length and bond angle between piperidine ring and cyclobutane, the introduction of the methoxy group at the phenyl group led to change in the chemical environment, thereby resulted in magnetic inequivalence. The $C_{2}-3,9$-diazatetraasterane 1 a showed an inversion symmetry center and twofold symmetry. It consisted of two parallel cyclobutane rings and four piperidine rings. The $\mathbf{2 b}$ were substituted by a methoxy group at the phenyl ring, its symmetry was broken with a non $C_{2}-3,9$ diazatetraasteranes. The conformation of the cyclobutane moiety of $\mathbf{2 b}$ was closed to a flat square with the bigger torsion angles (C6-C7-C8-C9) of $-3.2(2)^{\circ}$ than that angles (C1-C2-C5-C4) of -2.9(2) $)^{\circ}$ in 1a (Table 3). The four valence angles of $\mathbf{2 b}$ were more distortion, the four $\mathrm{C}-\mathrm{C}$ bonds are somewhat different.

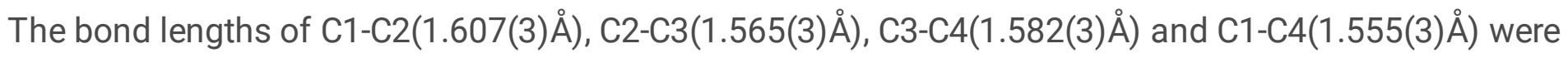
different and probably due to the phenyl is off the axis. The piperdine rings (N1 and N2) showed a bigger stern (C4-C5-C29, $\left.114.8^{\circ}>\mathrm{C} 8-\mathrm{C} 10-\mathrm{C} 11,114.0^{\circ}\right)$, and the bond lengths were little different (C4-C5,

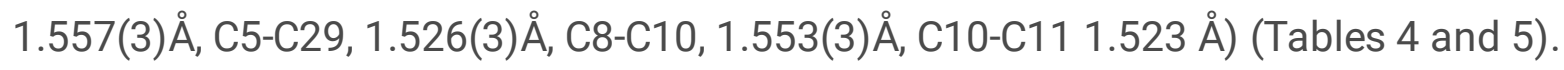

Table 3

Geometry of the cyclobutane (C1-C2-C5-C4) of $1 \mathrm{a}\left({ }^{\circ}\right.$ and $\AA$ )

\begin{tabular}{|cllllllll|}
\hline \multicolumn{3}{|l}{ Cyclobutane (C1-C2-C5-C4) } & \multicolumn{3}{c|}{ Cyclobutane (C4-C5-C2-C1) } \\
\hline \multirow{2}{*}{ Angle } & \multicolumn{3}{c}{ Distance } & Angle & \multicolumn{3}{c|}{ Distance } \\
\hline Quad & C1-C2-C5 & $90.5^{\circ}$ & C1-C2 & $1.553 \AA$ & C5-C2-C1 & $90.5^{\circ}$ & C5-C2 & $1.589 \AA$ \\
C2-C5-C4 & $90.3^{\circ}$ & C2-C5 & $1.589 \AA$ & C2-C5-C4 & $90.3^{\circ}$ & C2-C1 & $1.553 \AA$ \\
C5-C4-C1 & $89.2^{\circ}$ & C4-C5 & $1.563 \AA$ & C1-C4-C5 & $89.2^{\circ}$ & C4-C5 & $1.563 \AA$ \\
C4-C1-C2 & $89.8^{\circ}$ & C1-C4 & $1.613 \AA$ & C4-C1-C2 & $89.8^{\circ}$ & C1-C4 & $1.613 \AA$ \\
\hline
\end{tabular}

Table 4

Geometry of the piperidine ring (N1 and N2) $\left({ }^{\circ}\right.$ and $\AA$ ) of $2 b$

\begin{tabular}{|lllllllll|}
\hline \multicolumn{2}{|c}{ Piperidine(N1) } & \multicolumn{5}{c|}{ Piperidine(N2) } \\
\hline \multirow{2}{*}{ Angle } & & Distance & & Angle & \multicolumn{3}{c|}{ Distance } \\
stern & $\mathrm{C} 8-\mathrm{C} 10-\mathrm{C} 11$ & $114.0^{\circ}$ & $\mathrm{C} 8-\mathrm{C} 10$ & $1.553 \AA$ & $\mathrm{C} 6-\mathrm{C} 5-\mathrm{C} 29$ & $115.2^{\circ}$ & $\mathrm{C} 6-\mathrm{C} 5$ & $1.531 \AA$ \\
& & & $\mathrm{C} 10-\mathrm{C} 11$ & $1.523 \AA$ & & & $\mathrm{C} 5-\mathrm{C} 29$ & $1.526 \AA$ \\
\multirow{2}{*}{ prow } & $\mathrm{C} 2-\mathrm{C} 10-\mathrm{C} 11$ & $116.5^{\circ}$ & $\mathrm{C} 2-\mathrm{C} 10$ & $1.553 \AA$ & $\mathrm{C} 4-\mathrm{C} 5-\mathrm{C} 29$ & $114.8^{\circ}$ & $\mathrm{C} 4-\mathrm{C} 5$ & $1.557 \AA$ \\
& & & $\mathrm{C} 10-\mathrm{C} 11$ & $1.523 \AA$ & & & $\mathrm{C} 5-\mathrm{C} 29$ & $1.526 \AA$ \\
\hline
\end{tabular}


Table 5

Geometry of the cyclobutane (C1-C2-C3-C4, and C6-C7-C8-C9) of $2 \mathrm{~b}\left({ }^{\circ}\right.$ and $\AA$ )

\begin{tabular}{|cllllllll|}
\hline \multicolumn{3}{|l}{ Cyclobutane (C1-C2-C3-C4) } & \multicolumn{3}{l|}{ Cyclobutane (C6-C7-C8-C9) } \\
\hline \multirow{2}{*}{ Angle } & \multicolumn{3}{c}{ Distance } & Angle & \multicolumn{3}{c|}{ Distance } \\
\hline Quad & C1-C2-C3 & $89.1^{\circ}$ & C1-C2 & $1.607 \AA$ & C6-C7-C8 & $90.7^{\circ}$ & C6-C7 & $1.564 \AA$ \\
& C2-C3-C4 & $90.5^{\circ}$ & C2-C3 & $1.565 \AA$ & C7-C8-C9 & $90.6^{\circ}$ & C7-C8 & $1.570 \AA$ \\
C3-C4-C1 & $90.4^{\circ}$ & C3-C4 & $1.582 \AA$ & C8-C9-C6 & $89.7^{\circ}$ & C8-C9 & $1.555 \AA$ \\
C4-C1- C2 & $89.9^{\circ}$ & C4-C1 & $1.555 \AA$ & C9-C6-C7 & $88.9^{\circ}$ & C9-C6 & $1.607 \AA$ \\
\hline
\end{tabular}

\section{Conclusions}

The $C_{2}$-3,9-diazatetraasteranes 1 and non- $C_{2}$-3,9-diazatetraasteranes 2 were synthesized by the dimerization of diethyl 1,4-dihydropyridines-3,5-dicarboxylates. Their structures were characterized by ${ }^{1} \mathrm{H}$ NMR, ${ }^{13} \mathrm{C}$ NMR and single-crystal X-ray diffraction analysis. The NMR spectra analysis implied that the structural symmetry of molecules had effects on the NMR spectra of $\mathbf{1}$ and $\mathbf{2}$. Through the analysis of NMR spectra, we could conclude that the symmetry of the structure had a greater effect on the splitting of the methyl protons from the ethyl ester group and cyclobutane protons. Due to the structural symmetry, the methyl protons from the ethyl ester group and cyclobutane protons split into a group peak in 1 , and there were two groups of peaks in $\mathbf{2}$. Single-crystal X-ray diffraction analysis further explained their structures asymmetry and supported the consequence of NMR analysis. The changed geometry of the structure resulted in the spatial environment of the two methylene protons from ethyl ester group and cyclobutane protons, and increasing the complited split of them.

\section{Experimental Methods}

\subsection{Physical measurements}

The chemical reagents used in this experiment were all commercially available and used without additional purification. All reactions were monitored by TLC using silica-gel $60 \mathrm{~F} 254$ plates. ${ }^{1} \mathrm{H}$ NMR spectra and ${ }^{13} \mathrm{C}$ NMR spectra were recorded on a Bruker Advance 400 spectrometer at 400 and $100 \mathrm{MHz}$ using $\mathrm{CDCl}_{3}$ as the solvent and tetramethylsilane (TMS) as an internal standard at ambient temperature $\left(25^{\circ} \mathrm{C}\right)$. Melting points were determined on a XT-5A digital melting point apparatus without corrected. High-resolution mass spectral (HRMS) were recorded using a VG 70SE mass spectrometer from Manchester, UK, which was operated in electron impact or electrospray ionization mode. The samples were irradiated by a $365 \mathrm{~nm}$ LED lamp and $250 \mathrm{~W}$ medium-pressure mercury lamp while in quartz cuvettes.

\subsection{Chemical synthesis}




\subsubsection{Synthesis of $\mathrm{C}_{2}-3,9-$ diazatetraasterane $1 \mathrm{a}$ and $1 \mathrm{~b}$}

The synthesis of compounds 1 was performed according to our previous reported procedures [17]. To be specific, $y$-cyclodextrin $(0.5 \mathrm{mmol})$ aqueous solutions were added to the diethyl 1,4-dihydropyridine-3,5diicarboxylate (3 or $4,1 \mathrm{mmol})$ in $100 \mathrm{~mL}$ tetrahydrofuran. The resulting mixture was sonicated at $60{ }^{\circ} \mathrm{C}$ for $2 \mathrm{~h}$ and a clear homogeneous solution was obtained, which was subjected to irradiation of $250 \mathrm{~W}$ medium-pressure mercury lamp under nitrogen atmosphere for $8 \mathrm{~h}$ until complete conversion of the reactant (monitored by TLC). Subsequently, the reaction solution was concentrated under reduced pressure to remove organic solvents, the residues were recrystallized with dichloromethane/methanol $(V: V=4: 1)$ and afforded white solids as the target product.

Tetraethyl 6,12-diphenyl-3,9-diazahexacyclo [6.4.0.0 2,7. $0^{4,11} .0^{5,10}$ ] dodecane-1,5,7,11-tetracarboxylate (1a). Yield 80\%, M.P: 208.5-211.2 ${ }^{\circ} \mathrm{C} .{ }^{1} \mathrm{H}$ NMR $\left(400 \mathrm{MHz}, \mathrm{CDCl}_{3}\right): \delta(\mathrm{ppm}) 7.60-7.46(\mathrm{~m}, 4 \mathrm{H}), 7.19$ (t, $J=$ $7.2 \mathrm{~Hz}, 4 \mathrm{H}), 7.15$ (d, J = 7.1 Hz, 2H), $4.32(\mathrm{~s}, 4 \mathrm{H}), 4.01-3.87(\mathrm{~m}, 10 \mathrm{H}), 3.02$ (brs, 2H), 0.98 (t, J= $7.1 \mathrm{~Hz}$, $12 \mathrm{H}) .{ }^{13} \mathrm{C} \mathrm{NMR}\left(100 \mathrm{MHz}, \mathrm{CDCl}_{3}\right) \delta$ (ppm) 173.22, 137.43, 130.90, 127.80, 126.84, 60.84, 55.10, 48.82, 43.82, 13.89. HRMS (ESI), $\mathrm{m} / \mathrm{z}$ calcd 603.2701 for $\mathrm{C}_{34} \mathrm{H}_{39} \mathrm{~N}_{2} \mathrm{O}_{8}[\mathrm{M}+\mathrm{H}]^{+}$, found 603.2705. (CCDC: 1484747)

Tetraethyl 3,6,9,12-tetraphenyl-3,9-diazapentacyclo [6.4.0.0 2,7 $\left..0^{4,11} .0^{5,10}\right]$ dodecane - 1,5,7,11tetracarboxylate (1b). Yield 82\%, M.P: $255.8-256.6^{\circ} \mathrm{C}^{1} \mathrm{H}$ NMR $\left(400 \mathrm{MHz}, \mathrm{CDCl}_{3}\right) \delta(\mathrm{ppm}) 7.37$ (d, J= 3.9 $\mathrm{Hz}, 8 \mathrm{H}), 7.08$ (q, J=3.3, 2.4 Hz, 10H), 7.01-6.92 (m, 2H), $5.23(\mathrm{~s}, 4 \mathrm{H}), 4.05-3.93(\mathrm{~m}, 10 \mathrm{H}), 0.97$ (t, J= 7.1 $\mathrm{Hz}, 12 \mathrm{H}) .{ }^{13} \mathrm{C} \mathrm{NMR}\left(100 \mathrm{MHz}, \mathrm{CDCl}_{3}\right) \delta(\mathrm{ppm}) 172.8,149.7,136.6,130.2,129.5,128.0,127.0,120.4$, 117.5, 61.2, 57.9, 51.8, 44.1, 13.7. HRMS (ESI), $\mathrm{m} / \mathrm{z}$ calcd 755.3342 for $\mathrm{C}_{46} \mathrm{H}_{47} \mathrm{~N}_{2} \mathrm{O}_{8}\left[\mathrm{M}+\mathrm{H}^{+}\right.$, found 755.3346 .

\subsubsection{Synthesis of non- $\mathrm{C}_{2}-3,9$-diazatetraasterane $2 a$ and $2 b$}

The synthesis of compounds 2 was performed according to our previous reported procedures [13]. Dissolved an equivalent mixture of two different 1,4-dihydropyridine ( $\mathbf{3}$ and $\mathbf{4}$, or $\mathbf{3}$ and $\mathbf{5}, 10 \mathrm{mmol}$ ) in methanol, the solution was poured into a quartz cuvette, $\mathrm{N}_{2}$ was introduced as the protective gas. The ring-shaped internally illuminated LED lamp $(365 \mathrm{~nm}, 120 \mathrm{~W})$ was used as the light source. The reaction was completed about 10 hours (TLC monitoring). Then the reaction solution was concentrated, and purified by flash column chromatography (silica gel), recrystallized with ethyl acetate/n-hexane $(V: V=$ 1:4) to obtain the white solid.

Tetraethyl 3,6,12-triphenyl-3,9-diazapentacyclo [6.4.0.0 2,7. $\left.0^{4,11} .0^{5,10}\right]$ dodecane-1,5,7,11tetracarboxylate (2a). Yield 30\%, M.P: $199.5-201.3^{\circ} \mathrm{C} .{ }^{1} \mathrm{H} \mathrm{NMR}\left(400 \mathrm{MHz}, \mathrm{CDCl}_{3}\right): \delta(\mathrm{ppm}) 7.57-7.29$ (m, $6 \mathrm{H}), 7.24-7.03(\mathrm{~m}, 8 \mathrm{H}), 6.92-6.96(\mathrm{~m}, J=4.2 \mathrm{~Hz}, 1 \mathrm{H}), 5.21(\mathrm{~d}, 2 \mathrm{H}), 4.35(\mathrm{~d}, 2 \mathrm{H}), 4.03-3.91(\mathrm{~m}, 8 \mathrm{H}), 3.91$ (d, $J=10.2 \mathrm{~Hz}, 2 \mathrm{H}), 3.02$ (brs, $1 \mathrm{H}), 1.00(\mathrm{t}, J=7.1 \mathrm{~Hz}, 6 \mathrm{H}), 0.95(\mathrm{t}, J=7.0 \mathrm{~Hz}, 6 \mathrm{H}) .{ }^{13} \mathrm{C} \mathrm{NMR}(100 \mathrm{MHz}$, $\left.\mathrm{CDCl}_{3}\right) \delta(\mathrm{ppm}) 173.04,172.95,130.82,130.23,129.40,128.07,127.80,126.96,126.90,120.22,117.38$, 
$61.10,61.00,58.04,54.73,50.60,49.97,44.28,43.58,13.92,13.76$. HRMS (ESI), m/z calcd 679.3025 for $\mathrm{C}_{40} \mathrm{H}_{43} \mathrm{~N}_{2} \mathrm{O}_{8}[\mathrm{M}+\mathrm{H}]^{+}$, found 679.3028 .

Tetraethyl 6-phenyl-12-(3,4,5-trimethoxyphenyl)-3,9-diazapentacyclo [6.4.0.0 2,7.0 4,11 $.0^{5,10}$ ] dodecane1,5,7,11-tetracarboxylate (2b). Yield $28 \%$, M.P: $255.2-256.8{ }^{\circ} \mathrm{C} .{ }^{1} \mathrm{H} \mathrm{NMR}\left(400 \mathrm{MHz}, \mathrm{CDCl}_{3}\right): \delta(\mathrm{ppm}) 7.53$ (d, J= 7.2 Hz, 2H), 7.15-7.23 (m, 3H), $6.88(\mathrm{~s}, 2 \mathrm{H}), 4.33-4.34(\mathrm{~d}, 4 \mathrm{H}), 3.95-4.04(\mathrm{~m}, 8 \mathrm{H}), 3.91(\mathrm{~s}, 1 \mathrm{H}), 3.87$ $(\mathrm{s}, 1 \mathrm{H}), 3.81(\mathrm{~s}, 6 \mathrm{H}), 3.80(\mathrm{~s}, 3 \mathrm{H}), 3.04$ (brs, $2 \mathrm{H}), 1.05(\mathrm{t}, 6 \mathrm{H}), 1.00(\mathrm{t}, 6 \mathrm{H}) .{ }^{13} \mathrm{C} \mathrm{NMR}\left(100 \mathrm{MHz}, \mathrm{CDCl}_{3}\right) \delta$ (ppm) 173.2, 152.3, 137.3, 136.8, 133.0, 130.9, 127.8, 126.9, 108.5, 60.9, 60.8, 56.0, 55.2, 55.0, 48.9, 48.7, 44.0, 43.9, 14.0, 13.9. HRMS (ESI), $\mathrm{m} / \mathrm{z}$ calcd 693.3018 for $\mathrm{C}_{43} \mathrm{H}_{49} \mathrm{~N}_{2} \mathrm{O}_{11}[\mathrm{M}+\mathrm{H}]^{+}$, found 693.3021.(CCDC: 1537245)

\subsection{X-ray crystallography}

The X-ray data was collected on a Bruker D8 Venture system with graphite monochromatic Mo-Ka radiation $(\lambda=0.7107 \AA$ ). The structure was analyzed by SHELXS2008 method, then continuous Fourier and differential Fourier synthesis were carried out. The anisotropic displacement parameters of all nonhydrogen atoms on $\mathrm{F}^{2}$ were operated by using SHELXL2008, and the full matrix least square optimization of $F^{2}$ was carried out[18-21]. The hydrogen atoms were located from the positions of ideal geometry and refined on a riding model, and based on the corresponding $\mathrm{C}$-atoms $\left[U_{\mathrm{iso}}(\mathrm{H})=1.2 \mathrm{Ueq}(\mathrm{C})\right.$, or 1.5Ueq $\left.(\mathrm{C})\right]$. Structure refinement parameters for compounds $\mathbf{1 a}$ and $\mathbf{2 b}$ were given in Table 1 and crystallographic data were deposited with the Cambridge Crystallographic Data Center under deposition number CCDC1484747 (1a) and CCDC-1537245 (2b), respectively. 
Table 1

Crystallographic data of crystal of compound $1 \mathrm{a}$ and $\mathbf{2 b}$

\begin{tabular}{|c|c|c|}
\hline Basic parameters & $1 \mathrm{a}$ & $2 b$ \\
\hline Chemical formula & $\mathrm{C}_{34} \mathrm{H}_{38} \mathrm{~N}_{2} \mathrm{O}_{8}$ & $\mathrm{C}_{34} \mathrm{H}_{44} \mathrm{~N}_{2} \mathrm{O}_{11}$ \\
\hline Formula weight & 602.66 & 692.74 \\
\hline Calculated density $\left(\mathrm{Mg} \mathrm{m}^{-3}\right)$ & 1.320 & 1.362 \\
\hline Wavelength $\lambda(\AA)$ & 0.71073 & 0.71073 \\
\hline Cryatl system, space group & Triclinic, P-1 & Monoclinic, $\mathrm{P} 2{ }_{1} / \mathrm{n}$ \\
\hline \multirow[t]{6}{*}{ Unit cell dimensions } & $\mathrm{a}=7.4749(12)$ & $\mathrm{a}=7.0677(17)$ \\
\hline & $\mathrm{b}=12.4923(19)$ & $b=38.091(8)$ \\
\hline & $c=16.607(3)$ & $c=12.609(3)$ \\
\hline & $a=89.034(10)^{\circ}$ & $a=90.00$ \\
\hline & $\beta=86.956(10)^{\circ}$ & $\beta=95.486(5)$ \\
\hline & $Y=78.183(7)^{\circ}$ & $Y=90.00$ \\
\hline Volume $\mathrm{V}\left(\AA^{3}\right)$ & $1516.7(4)$ & $3379.0(14)$ \\
\hline Z & 4 & 4 \\
\hline Absorption coefficient $\left(\mathrm{mm}^{-1}\right)$ & 0.094 & 0.101 \\
\hline$F(000)$ & 640 & 1472 \\
\hline Crystal size $\left(\mathrm{mm}^{3}\right)$ & $0.20 \times 0.18 \times 0.12$ & $0.20 \times 0.18 \times 0.12$ \\
\hline$\theta$ range for data collection $\left(^{\circ}\right)$ & $3.10-27.58$ & $3.09-27.50$ \\
\hline Temperature (K) & $113(2)$ & $113(2)$ \\
\hline diffraction illuminant & Mo K\a & Mo K\a \\
\hline R factor & 0.0736 & 0.0991 \\
\hline
\end{tabular}

\section{Declarations}

Supplementary information Crystallographic data for structural analysis reported in this paper were deposited with the Cambridge Crystallographic Data Centre under deposition number CCDC-1484747 and CCDC-1537245. These data can be obtained free of charge at www.ccdc.cam.ac.uk/conts/retrieving.html. 
Author contribution Runzhi Sun conceived the presented idea and performed preparation and preprocessing of data and wrote the manuscript with support from Xiuqing Song and Fan Xie. Runzhi Sun, Xiuqing Song and Fan Xie carried out the synthesis and characterization of the compounds. Hong Yan and Huiqin Wang conceived the presented idea and supervised this work. All authors discussed the results and contributed to the final manuscript.

Funding This work was financially supported by the 2019 Beijing Natural Science Foundation (No. 2192004).

Data availability The data used to support the findings of this study are available from the corresponding author upon request.

Code availability Not applicable

\section{Compliance with ethical standards}

Consent to participate Our current study did not involve human subject and has not used living animals, etc.

Conflict of interest The authors declare that they have no known competing financial interests or personal relationships that could have appeared to influence the work reported in this paper.

\section{References}

1. Kramer W, Schirmer U, Jeschke P, Witschel M (2011)

2. Wanka L, Iqbal K, Schreiner PR (2013) Chem Rev 113:3516-3604. doi:10.1021/cr100264t

3. Stockdale TP, Williams CM (2015) Chem Soc Rev 44: doi:10.1039/c4cs00477a

4. Poplata S, Troster A, Zou YQ, Bach T (2016) Chem Rev 116:9748-9815. doi:10.1021/acs.chemrev.5b00723

5. Hans-Giinter F, H-M H, Hans M, Goran A et al, (1976)

6. Cookson RC, Cox DA, Hudec J (1961) Journal of the Chemical Society (Resumed). doi: 10.1039/jr9610004499

7. Andreas Hilgeroth A B (1999) Arch. Pharm. Pharm. Med. Chem 332: 3-5. doi: 10.1002/(SICI)15214184(19991)332:1<3::AID-ARDP3>3.0.C0;2-1.

8. Billich A H a A (1999) Arch. Pharm. Pharm. Med. Chem. 332: 380-384. doi: 10.1002/(SICI)15214184(199911)332:11<380::AID-ARDP380>3.0.C0;2-.

9. Andreas Hilgeroth MW, Billich A (1999) J Med Chem 42:4729-4732. doi:10.1021/jm991115k

10. Richter M, Gyemant N, Molnar J, Hilgeroth A (2006) Arch Pharm (Weinheim) 339:625-628. doi:10.1002/ardp.200600094 
11. Wollmann J, Baumert C, Erlenkamp G, Sippl W, Hilgeroth A (2008) Chembiochem 9:874-878. doi:10.1002/cbic.200700646

12. Li P, Wang S, Yan* H (2019) biological \& pharmaceutical bulletin 42: doi: $10.1248 / \mathrm{bpb} . b 18-00705$

13. Fan Q, Tan H, Li P, Yan H (2018) New J Chem 42:16795-16805. doi:10.1039/c8nj02192a

14. Fan Q, Wang Y, Yan H (2018) Struct Chem 29:871-879. doi:10.1007/s11224-017-1061-5

15. Ivashchenko DA, Cerqueira N M F S A, Magalhães AL (2021) Struct Chem doi:10.1007/s11224-02101726-w

16. Song XQ, Wang HQ, Yan H, Ni CL, Zhong RG (2011) J Mol Struct 1006:489-493. doi:10.1016/j.molstruc.2011.09.056

17. Sun W, Fan Q, Yan H (2018) J Photochem Photobiol A 359:33-39.

doi:10.1016/j.jphotochem.2018.03.046

18. Shelxs GM, Shelxs GM, Shelxs GM, Shelxs GM, Shelxs G M (2008)

19. Kunz PC, Acw A, Bernhard SB, Mo KR, Xcalibur O, Ccd R (2010)

20. Braun J, Boittiaux Al, Tilborg AA, Didier A, Lambert B, Johan W A (2010)

21. Fejfarová K, Aem B, Dehno A, Khalaji C, Xcalibur O D (2010)

\section{Figures}

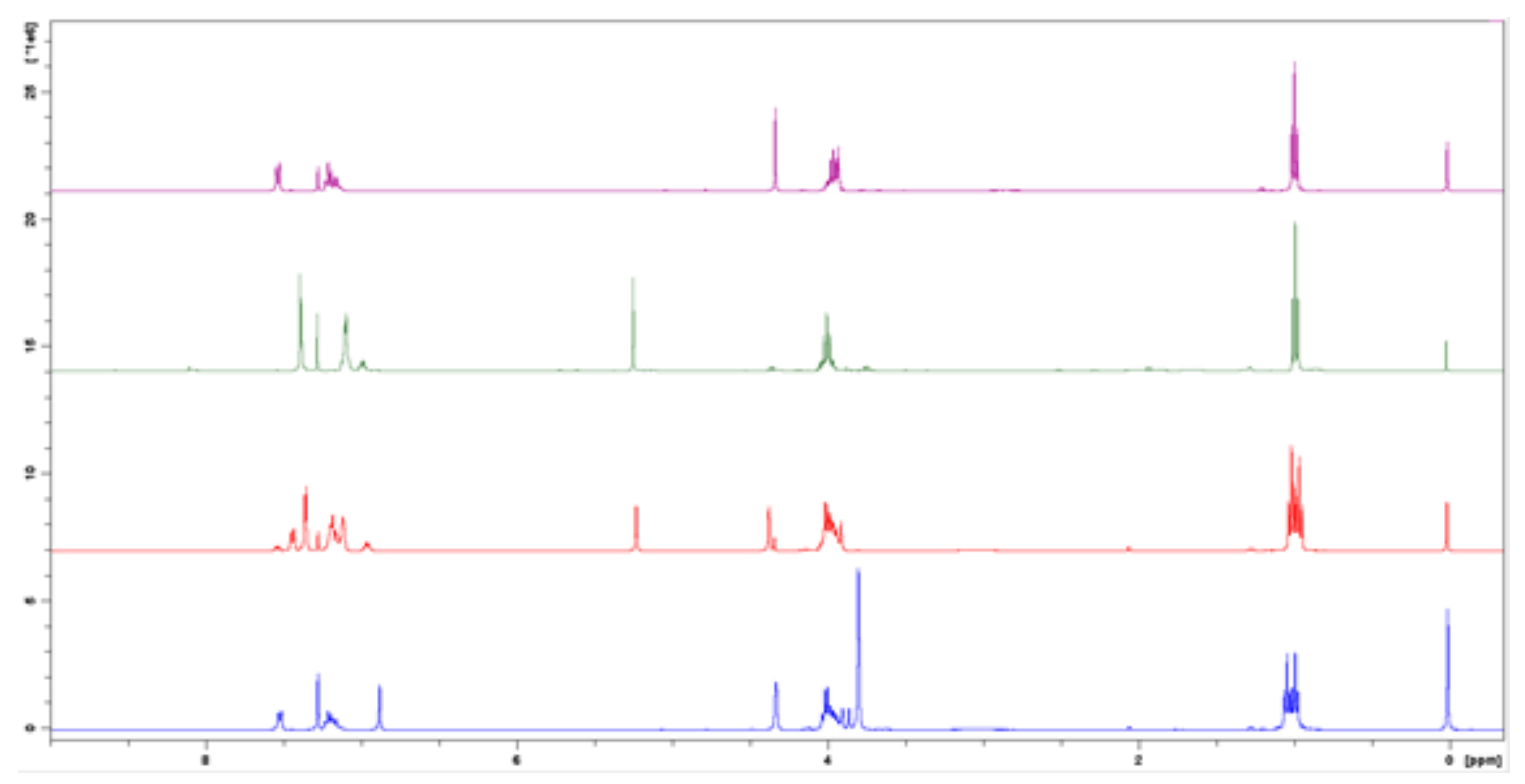

Figure 1

Comparison of $1 \mathrm{H}$ NMR spectrum of $1 \mathrm{a}, 1 \mathrm{~b}, 2 \mathrm{a}$ and $2 \mathrm{~b}$ in $\mathrm{CDCl} 3$ 


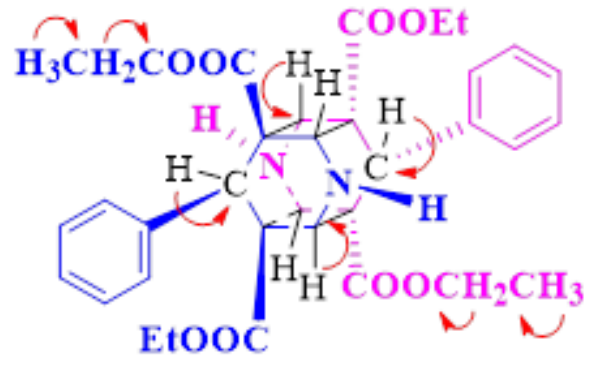

A

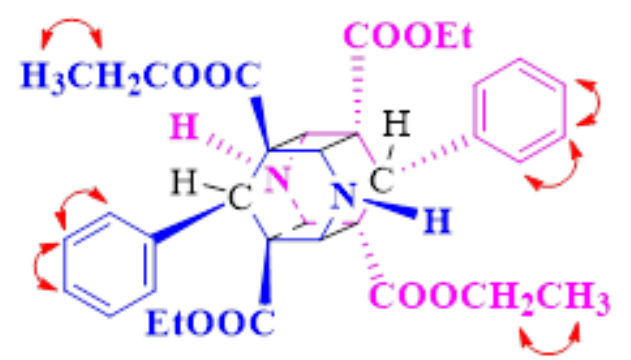

B

Figure 2

Key HSQC correlations $(\mathrm{H} \rightarrow \mathrm{C})$ and $\mathrm{H}-\mathrm{H} \operatorname{COSY}(\mathrm{H} \rightarrow \mathrm{H})$ correlations of $1 \mathrm{a}$

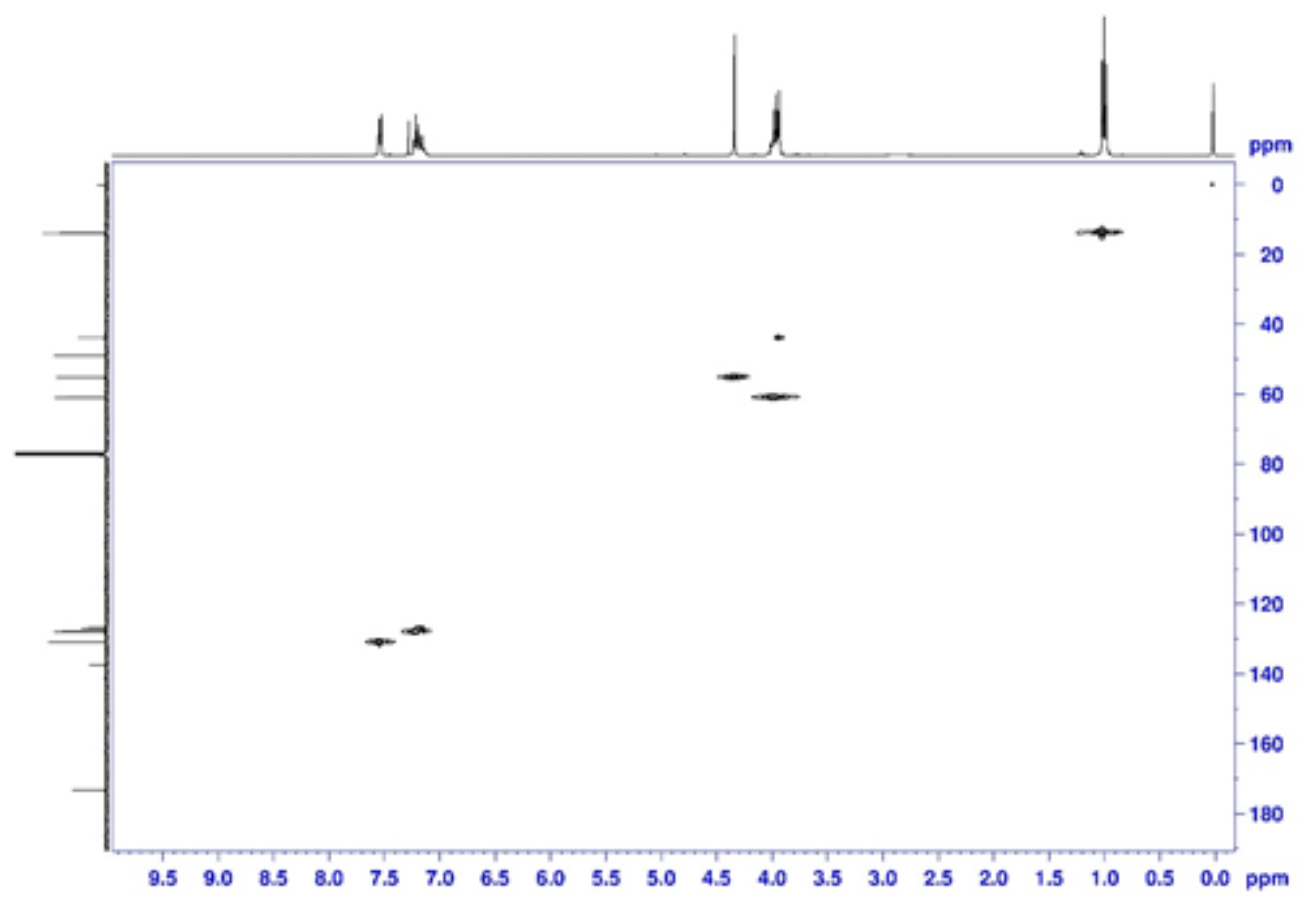

Figure 3

Expansion of HSQC spectrum of $1 \mathrm{a}$ in $\mathrm{CDCl} 3$ 


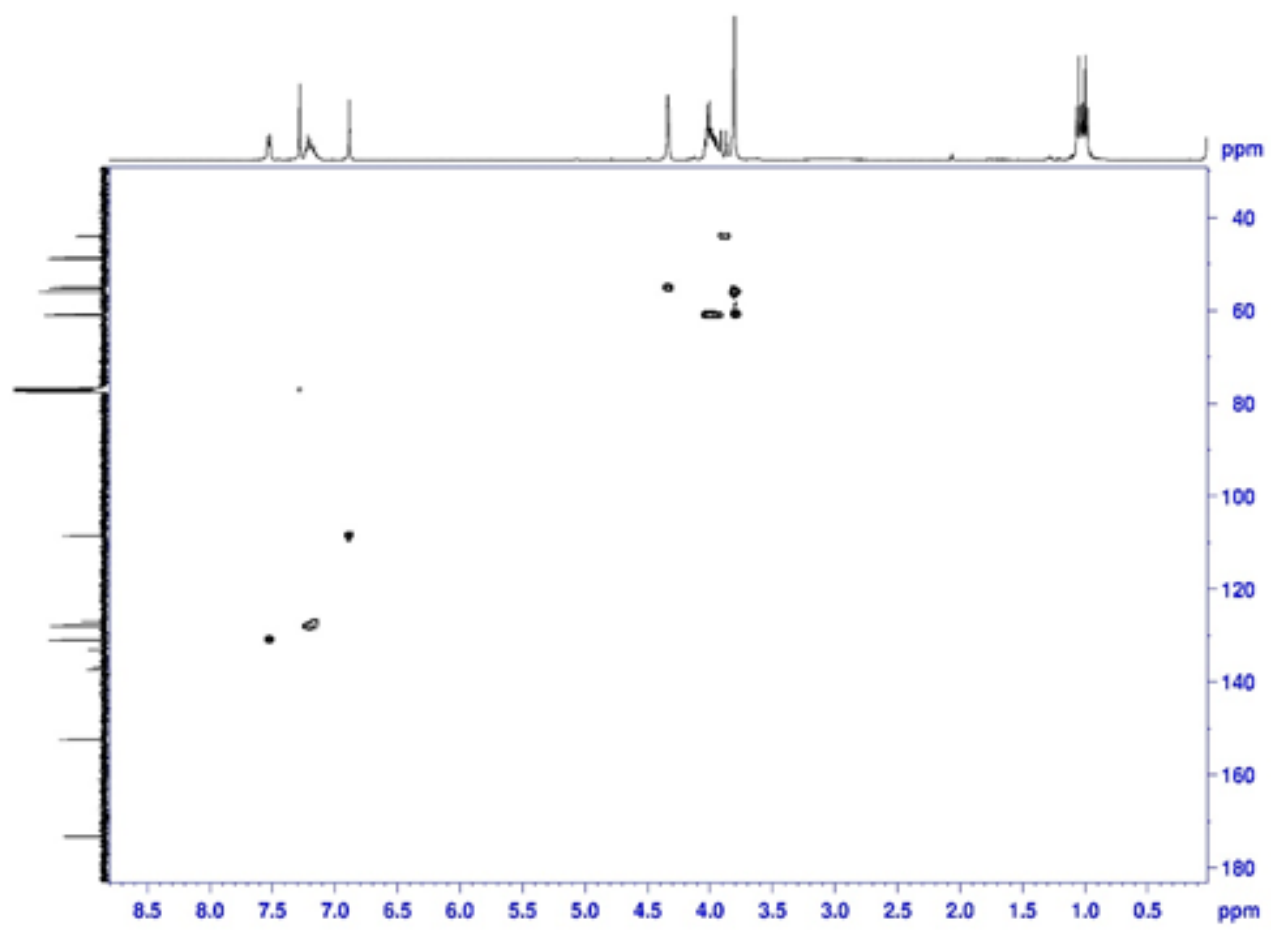

Figure 4

Expansion of $\mathrm{HSQC}$ spectrum of $2 \mathrm{~b}$ in $\mathrm{CDCl} 3$

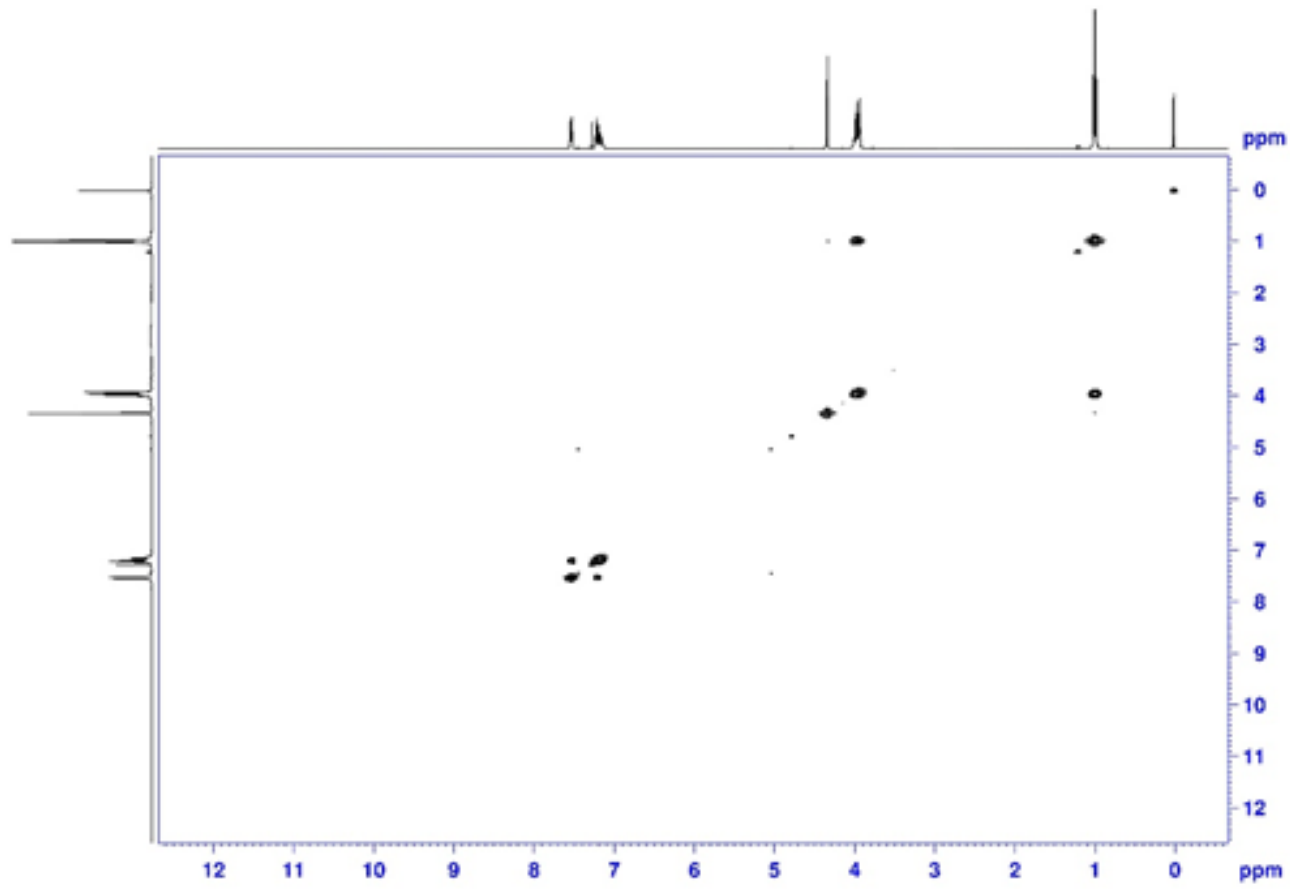

Figure 5 


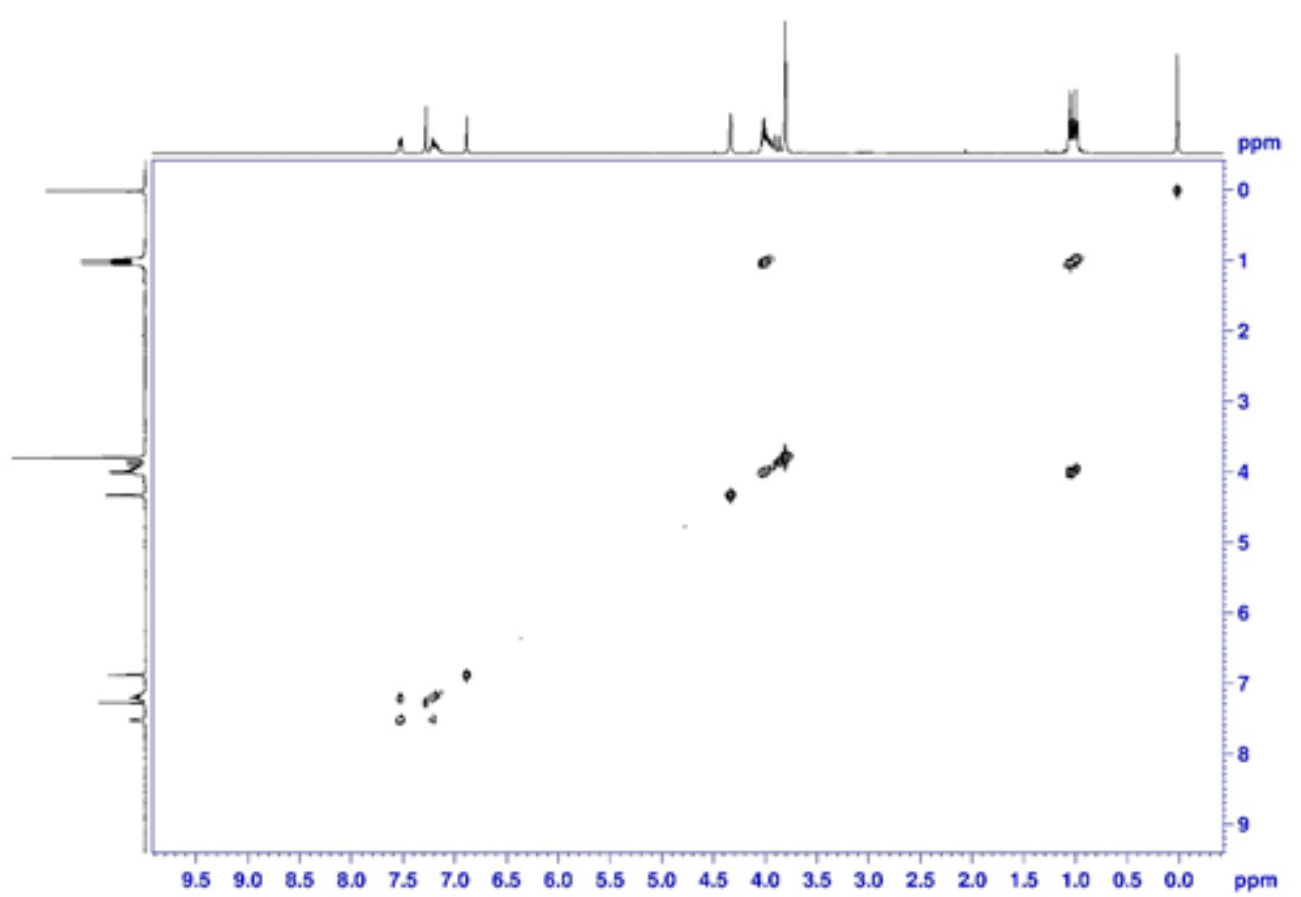

Figure 6

Expansion of $\mathrm{H}-\mathrm{H}$ COSY spectrum of $2 \mathrm{~b}$ in $\mathrm{CDCl} 3$

A

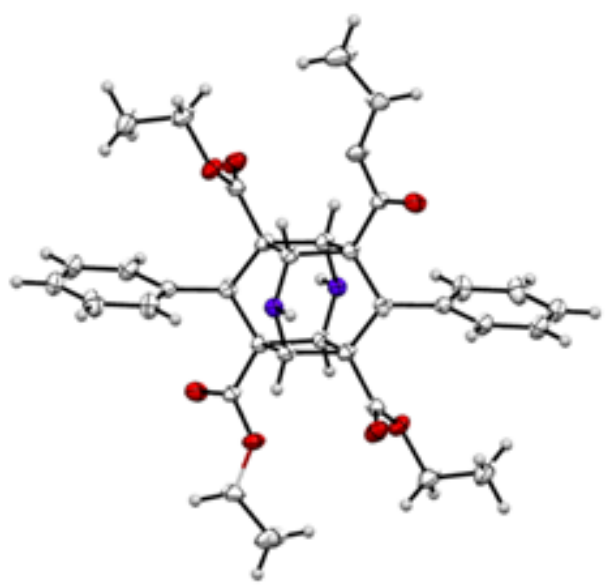

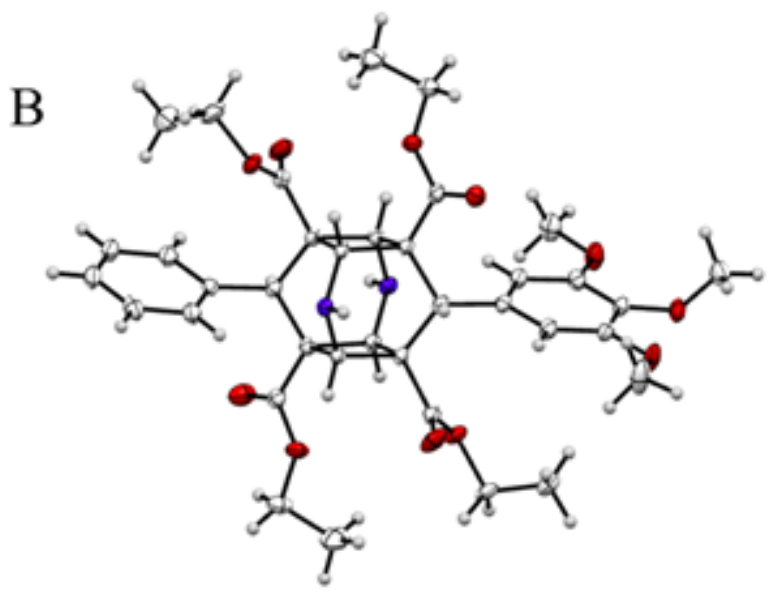

Figure 7

Single-crystal X-ray structures of $1 \mathrm{a}$ and $2 \mathrm{~b}$

\section{Supplementary Files}

This is a list of supplementary files associated with this preprint. Click to download.

- Scheme01.png 
- Scheme02.png

Page 16/16 